Article

\title{
Theoretical Description of Carbon Felt Electrical Properties Affected by Compression
}

\author{
Moshe Averbukh ${ }^{1, *}$ (1) and Svetlana Lugovskoy ${ }^{2}$ \\ 1 Department of Electric/Electronic Engineering, Ariel University, Kiriat HaMada, Ariel 4070000, Israel \\ 2 Department of Chemical Engineering/Materials, Ariel University, Kiriat HaMada, Ariel 4070000, Israel; \\ svetlanalu@ariel.ac.il \\ * Correspondence: mosheav@ariel.ac.il; Tel.: +972-528814120
}

Received: 11 August 2019; Accepted: 23 September 2019; Published: 26 September 2019

Featured Application: Vanadium and other electrolyte flow batteries.

\begin{abstract}
Electro-conductive carbon felt (CF) material is composed by bonding together different lengths of carbon filaments resulting in a porous structure with a significant internal surface that facilitates enhanced electrochemical reactions. Owing to its excellent electrical properties, CF is found in numerous electrochemical applications, such as electrodes in redox flow batteries, fuel cells, and electrochemical desalination apparatus. CF electro-conductivity mostly arises from the close contact between the surface of two electrodes and the long carbon fibers located between them. Electrical conductivity can be improved by a moderate pressing of the $\mathrm{CF}$ between conducting electrodes. There exist large amounts of experimental data regarding CF electro-conductivity. However, there is a lack of analytical theoretical models explaining the $\mathrm{CF}$ electrical characteristics and the effects of compression. Moreover, $\mathrm{CF}$ electrodes in electrochemical cells are immersed in different electrolytes that affect the interconnections of fibers and their contacts with electrodes, which in turn influence conductivity. In this paper, we investigated both the role of CF compression, as well as the impact of electrolyte characteristics on electro-conductivity. The article presents results of measurements, mathematical analysis of CF electrical properties, and a theoretical analytical explanation of the CF electrical conductivity which was done by a stochastic description of carbon filaments disposition inside a CF frame.
\end{abstract}

Keywords: Carbon felt; electrical conductivity; theoretical model

\section{Introduction}

Carbon Felt (CF) is used as electrode material in a variety of electrochemical applications [1-7]. Currently, its most prominent utilization is in the vanadium redox and other flow type batteries owing to its good electrical conductivity, hydraulic permeability, and durability in strong acid and alkali electrolytes. In particular, good electrical conductivity arises from the movement of electrons through the carbon filaments to reach the electrolyte [8-20].

CF conductivity is determined by the carbon fibers comprising the felt structure and which connect simultaneously to both electrodes. Conductivity is well known to be improved by felt compression. With slight pressure on a felt, the density of the fibers is increased, producing additional self-interconnections of fibers and better contact with the substrate of the electrodes. However, felt compression also decreases the interstitial volume, and therefore, reduces the average cross-section of micro-channels linking pores inside a felt framework. The result is an increase in the CF hydraulic resistance obstructing electrolyte flow through the electrode. Electrochemical researchers, design 
engineers, and others need to consider both the electrical and physical properties of CF for optimal performance in many electrochemical applications.

A tremendous amount of research work [21-30] has been carried out to investigate and measure the properties of CF. Weber et al. [31], for example, suggested a ladder circuit comprising multiple equal resistances that model resistivity for the explanation CF conductivity. However, this model does not explain sufficiently the decrease of CF resistivity during its compression.

Choe et al. [32] measured physical parameters of rayon-based CF manufactured by Mersen Co in large sheets with a width of several $\mathrm{mm}$ to a few $\mathrm{cm}$.

The structure of CF exhibits a significant stochastic framework; therefore, theoretical analyses previously developed, as a rule, used many simplifying assumptions. Thus, results and conclusions required correction coefficients and frequently differed from experimental test results. Moreover, it proved difficult to generalize results to other similar cases. Therefore, many investigations concerning electrical conductivity of CF were conducted for specific applications with the generalization obtained by results from mathematical formulations. For example, measurements of $\mathrm{CF}$ electrical resistivity (conductivity) were carried out for furnace heating elements [3].

Among the reports, work by Johan et al. [26] was the first to examine conductivity of CFs used in electrochemical applications. These authors studied a new bipolar cell with a proton-exchange membrane, where flat electrodes were made of long carbon fiber assemblies like CF structure to facilitate electrical current flow. The main aim of the investigation was the amplification of the cell current that could be enhanced by the increase of electrodes conductivity. They found a two-fold increase of stress on the electrodes which causes a 2.5-times increase of CF conductivity and current, which in turn led to enhanced electrochemical reactions. At the same time, oxidative reactions are enhanced at the anode electrode, and reduction reactions are enhanced at the cathode. Accordingly, electrodes resistivity were measured based on the area-specific resistance (ASR), which represents the specific resistance in the perpendicular-plane direction of CF electrodes. ASR was found to be a function of the compression of felt, and it allows the resistance estimation of any electrode having its own specific dimensions. It is important to emphasize the usefulness of ASR for describing CF conductivity appearing in this work for the first time. The usefulness of ASR is witnessed by its usage in multiple published studies [27-30].

The sharp decrease of CF ASR during compression was observed in all experiments. The only difference could be observed in heterogeneous mathematical formulations for describing $\mathrm{CF}$ conductivity. ASR magnitude was characterized [26], for example, by an exponential function. Subsequent results of ASR versus CF compression coefficient were obtained [27]. Since CF could be bound to the surface of the electrode either by simple mechanical contact or by adhesives, the influences on ASR of these materials were investigated. Assemblies of different electrode plates were examined. The same sharp diminishing of resistance versus compression pressure was detected, which may be described by an exponential formula, although with different exponent coefficients. Predictably, these coefficients depend on the type of adhesive used; however, the significant achievement of Johan et al.'s work [26] is that for the first time their values were represented as a function of the kind of adhesive and the type of electrodes design.

More recent reports have focused on experimental measurements of CF conductivity [28-30] and have shown influences of felt porosity and specific resistivity of the carbon material. For example, the analytical expression of ASR (named as a specific electrical resistivity and denoted as $\rho_{\text {felt }}$ [28]) was defined by the following expression:

$$
\rho_{\text {felt }}=\frac{4}{(1-\lambda)} \rho_{\text {carbon }}
$$

where $\lambda$ signifies relative felt porosity and is equal to the volume ratio of its empty space to the total felt. Expression (1) was found to be in good agreement with the experimental results. 
Experimental measurements of ASR for $\mathrm{CF}$ electrodes used in vanadium redox batteries were carried out in [32]. ASR, in this work, is denoted as $R_{A S R} \cdot R_{A S R}$ with units of $\mathrm{m} \Omega \cdot \mathrm{cm}^{-2}$ was estimated by Equation (2) below, where $V_{f}$ denotes the percentage of fiber volume. Notably, $V_{f}$ is expressed by the porosity $(\lambda)$, i.e., $\mathrm{V}_{\mathrm{f}} / 100=1-\lambda$. Then

$$
R_{A S R}=144.456 \cdot\left(3-\frac{10}{V_{f}}\right)^{-1.117}
$$

The exponential type of expression (2) is valid for various electrochemical applications. However, all the specific constants in Equation (2) are only applicable to the description of resistance of electrodes used in special vanadium redox batteries. The use of this expression in other applications will lead to considerable loss of accuracy. This is because an actual type of carbon material and the manufacturing process of CF were neglected in this work. Therefore, this circumstance significantly diminishes the value of the presented results. Furthermore, resistance measurements were carried out in dry conditions, i.e., in the air only. However, supplementary investigations performed by the authors [21] showed the effects of liquid dielectric constant (relative permittivity) on CF conductivity. The electrical conductivity of $\mathrm{CF}$ seems to be influenced by the properties of these liquids conducive to the penetration of fluid between fibers and their separation or conversely, to their convergence and additional contacts. The resistance of CF is known to increase through a diminishing interconnection of density of fibers. On the other hand, the resistance is diminished by additional interconnections [21]. It is possible to summarize that currently, many results regarding CF electrical conductivity have been obtained, processed, and described. However, a strict analytical explanation of the CF electrical resistance phenomena has not been propounded. This could be explained by the significantly stochastic structure of felt that was not considered in previous works. Known theoretical approaches used relatively simplified assumptions, reducing the applicability of their results. The requirement to find a more comprehensive analytical explanation of CF conductivity remains an actual and important task.

The present work is aimed at developing a rigorous analytical model of felt conductivity by considering the stochastic character of filaments dimensions and dispositions inside $\mathrm{CF}$, as well as their random contacts. In addition, a parallel study of electrical properties of a CF immersed in different dielectric liquids was conducted. The experimental measurements were compared with the results of the developed theoretical model.

\section{Methodology of Experimental Research}

The main objective of this research was to investigate and determine the electrical properties of CFs in a wide range of external conditions.

\subsection{Characteristics of $C F$}

In this work, rayon-based CF material made from high-quality carbon fibers, acquired from Mersen Corp (Mersen, Greenville, MI, USA) [33], was used. A micrograph showing the structure of the CF is depicted in Figure 1. Additional characteristics of this CF are tabulated in Table 1 [33]. 


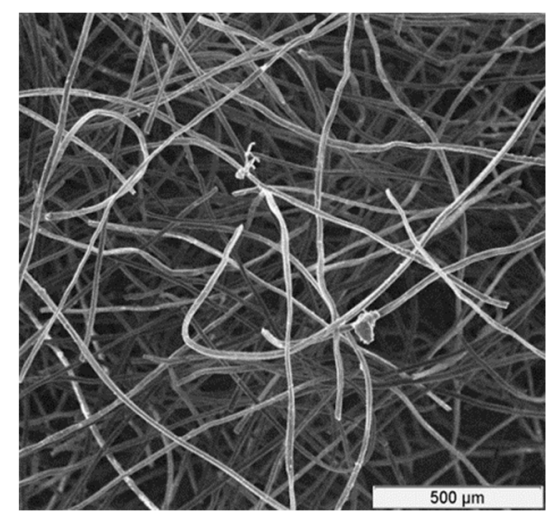

Figure 1. A magnified picture of CF structure.

Table 1. Mechanical properties of a CF.

\begin{tabular}{lcc}
\hline \multicolumn{1}{c}{ Fiber Diameter, $\boldsymbol{\mu m}$} & Average & Standard Deviation \\
\cline { 2 - 3 } & $\mathbf{1 9 . 2}$ & $\mathbf{1 . 6 6}$ \\
\hline Felt density, $\left[\mathrm{kg} / \mathrm{m}^{3}\right], \rho_{f}$ & 88 & - \\
Carbon density, $\left[\mathrm{kg} / \mathrm{m}^{3}\right], \rho_{c}$ & 1954 & - \\
Porosity, $[\%], \lambda$ & 95.5 & - \\
Relative carbon volume, p.u. $[\%], \mathrm{V}$ & $0.045(4.5 \%)$ & - \\
Specific felt surface, $\left[\mathrm{m}^{-1}\right], \mathrm{S}$ & $9.8 \cdot 10^{3}$ & - \\
\hline
\end{tabular}

A special cell for testing was fabricated (Figure 2); the design allows measurements of electrical conductivity for compressed CF. Cell dimensions (Figure 3) for felt samples were of $30 \times 100 \mathrm{~mm}$. Each felt sample was placed between two identical thin copper sheets of a similar size to that of the felt sample. These copper sheets are placed below and over CF as it seems in Figure 2. Felt thicknesses, denoted as $\mathrm{h}$, diminished from 6.6 to $1.2 \mathrm{~mm}$ by tightening four screw nuts. The uniformity of the felt thickness is measured by an electronic caliber having $0.01 \mathrm{~mm}$ accuracy.

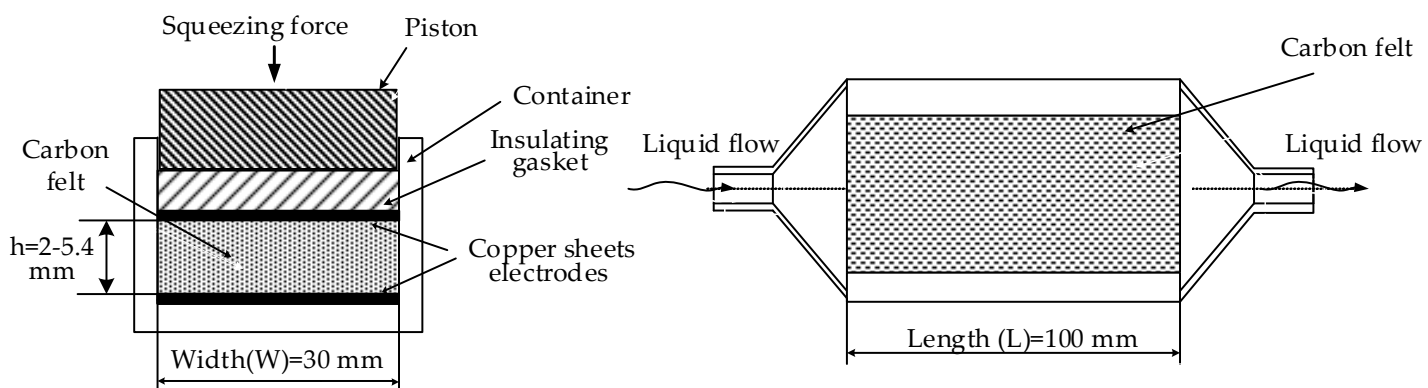

Figure 2. Special experimental cell for conductance measurements.
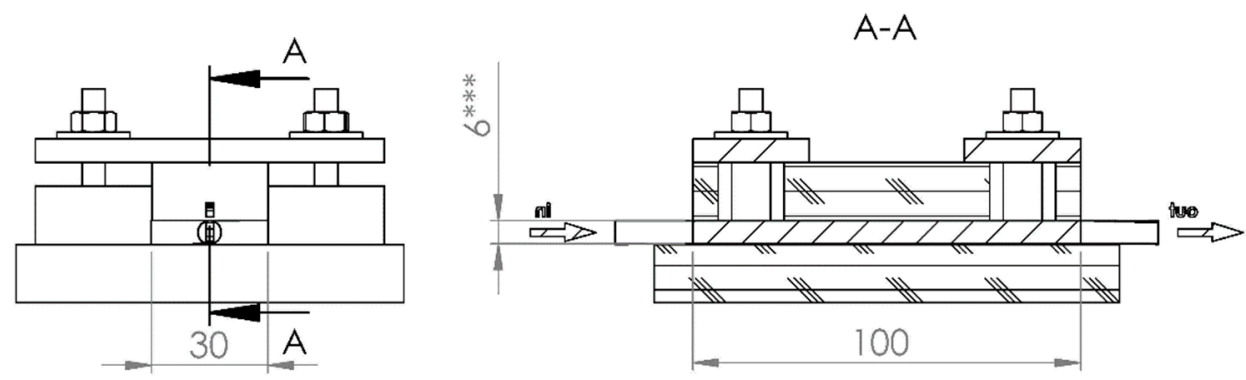

Figure 3. Dimensions of the experimental cell (from [21]).

Electrical conductivity was measured between copper sheets simulating electrode substrates. 
The electrical conductivity of compressed CFs was initially measured in dry conditions. This was then repeated after immersing CFs in three different liquids of dissimilar electrical permittivity including glycerol, ethanol ( $96 \%$ strength) and cyclohexane. Conductivity estimation was provided by a bench-type four-probe R/L/C METER IX 3131B (Metrix Co., Dubuque, IA, USA) able to measure resistance $\left(\mathrm{R}_{\mathrm{ac}}\right.$ ) by applying $100 \mathrm{~Hz}, 120 \mathrm{~Hz}, 1 \mathrm{kHz}$, and $10 \mathrm{kHz}$ AC frequencies with an error of $\sim 0.6 \%$. In addition, the resistance $\left(R_{\mathrm{dc}}\right)$, by applying $D C$ voltage, was measured by a Fluke multimeter.

\subsection{Conductivity Measurements}

The results of resistance measurements are presented here both for dry felt electrodes and for those immersed in several dielectric (nonconductive) liquids. Dielectric liquids were used in order to eliminate the influences of the ionic conductivity of the liquid itself on the resistance of the felt. A major assumption for the conductivity description was that the resistance of the felt is determined mainly by the density of filament interconnections within the felt along with the density of filament contacts with the electrode surfaces.

Three dissimilar dielectric liquids were chosen: glycerol, ethanol, and cyclohexane, with significantly different values of relative electric permittivity's (dielectric constant) $\varepsilon_{\mathrm{r}}$. Below is Table 2, which represents the most important physical parameters of each. It should be noted that resistance properties of carbon material used for CF producing are represented in Table 2 by specific electrical conductivity measured in $(\Omega \cdot \mathrm{cm})^{-1}$.

Table 2. Physical parameters of glycerol, alcohol, and cyclohexane.

\begin{tabular}{cccc}
\hline Parameter & \multicolumn{3}{c}{ Liquid } \\
\cline { 2 - 4 } & Glycerol & Ethanol & Cyclohexane \\
\hline Density, $\left[\mathrm{g} / \mathrm{cm}^{3}\right]\left(25^{\circ} \mathrm{C}\right)$ & 1.26 & 0.789 & 0.8 \\
Relative permittivity, $\varepsilon_{\mathrm{r}},\left(0.57 \mathrm{MHz}, 25^{\circ} \mathrm{C}\right)$ & $\sim 42.5$ & $\sim 21.6$ & $\sim 2.02$ \\
Specific electrical conductivity, $\left[(\Omega \cdot \mathrm{cm})^{-1}\right], 25^{\circ} \mathrm{C}$ & $5 \cdot 10^{-8}$ & $\sim 1 \cdot 10^{-6}$ & $<5 \times 10^{-9}$ \\
Viscosity, $[\mathrm{Pa} \cdot \mathrm{s}], 20^{\circ} \mathrm{C}\left(30^{\circ} \mathrm{C}\right)$ & $141(61.2)$ & $\sim 0.11$ & 0.61 \\
\hline
\end{tabular}

Resistance values of dry CF are shown in Table 3 measured in AC and DC currents. For ensuring the exactness of tests, the conductivity of each liquid (without a CF presence in the cell) was measured preliminary. Only if the conductivity had a zero value (in accordance with the exactness of applied devices), the following experiments with CF were produced.

As a measure of felt conductivity the average square conductivity (ASC) $\left(1 /\left(\Omega \cdot \mathrm{cm}^{2}\right)\right.$ parameter was chosen equal to the reciprocal of the total resistance of the felt in the experimental cell multiplied by its area. The indicator of conductivity was taken its average value obtained for alternating and direct currents.

Where: h-current CF width, $\mathrm{mm} ; \mathrm{R}_{\mathrm{dc}}$ - resistance is measured by direct current (DC), $\Omega ; \mathrm{R}_{\mathrm{ac}}-$ resistance is measured by alternate current (AC), $\Omega$.

The measurements of CF resistivity, whose results are shown in Table 3, confirm the decrease of $\mathrm{CF}$ resistivity during compression applied perpendicular to the surface. Initially, CF resistivity falls precipitously; subsequently, the resistance decrease slows. The measurements results for CF immersed in glycerol, alcohol, and cyclohexane are placed in Appendix A. The typical change of relative resistivity for $\mathrm{CF}$ in ethanol is presented in Figure 4. Further analysis is given in the following section. 
Table 3. Resistance of dry CF.

\begin{tabular}{|c|c|c|c|c|c|c|c|c|}
\hline \multirow{4}{*}{\multicolumn{2}{|c|}{ Parameter }} & \multicolumn{7}{|c|}{$\mathrm{h}, \mathrm{mm}$} \\
\hline & & 6.3 & 6.1 & 4.9 & 4.45 & 3.7 & 1.55 & 1.1 \\
\hline & & \multicolumn{7}{|c|}{ Volume decrease, $\%$} \\
\hline & & 0 & 3 & 22 & 29 & 41 & 75 & 83 \\
\hline \multicolumn{2}{|l|}{$\mathrm{Rdc}, \Omega$} & 0.65 & 0.22 & 0.13 & 0.1 & 0.09 & 0.07 & 0.08 \\
\hline \multirow{4}{*}{ Rac, $\Omega$} & $100 \mathrm{~Hz}$ & 0.74 & 0.17 & 0.098 & 0.092 & 0.08 & 0.059 & 0.059 \\
\hline & $120 \mathrm{~Hz}$ & 0.737 & 0.168 & 0.095 & 0.095 & 0.082 & 0.061 & 0.058 \\
\hline & $1 \mathrm{kHz}$ & 0.737 & 0.17 & 0.101 & 0.093 & 0.086 & 0.061 & 0.057 \\
\hline & $10 \mathrm{kHz}$ & 0.665 & 0.163 & 0.095 & 0.091 & 0.08 & 0.063 & 0.058 \\
\hline \multicolumn{2}{|l|}{ Rrel, $p, u$} & 1.000 & 0.252 & 0.147 & 0.133 & 0.118 & 0.089 & 0.088 \\
\hline \multicolumn{2}{|c|}{ ASCDC, $1 /\left(\Omega \cdot \mathrm{cm}^{2}\right)$} & 0.051 & 0.152 & 0.256 & 0.333 & 0.370 & 0.476 & 0.417 \\
\hline \multirow{4}{*}{$\mathrm{ASC}_{\mathrm{AC}}, 1 /\left(\Omega \cdot \mathrm{cm}^{2}\right)$} & $100 \mathrm{~Hz}$ & 0.045 & 0.196 & 0.340 & 0.362 & 0.417 & 0.565 & 0.565 \\
\hline & $120 \mathrm{~Hz}$ & 0.045 & 0.198 & 0.351 & 0.351 & 0.407 & 0.546 & 0.575 \\
\hline & $1 \mathrm{kHz}$ & 0.045 & 0.196 & 0.330 & 0.358 & 0.388 & 0.546 & 0.585 \\
\hline & $10 \mathrm{kHz}$ & 0.050 & 0.204 & 0.351 & 0.366 & 0.417 & 0.529 & 0.575 \\
\hline \multicolumn{2}{|c|}{ Average ASC, $1 /\left(\Omega \cdot \mathrm{cm}^{2}\right)$} & 0.0474 & 0.1893 & 0.3257 & 0.3543 & 0.3996 & 0.5326 & 0.5432 \\
\hline
\end{tabular}

Relative CF electrical resistivity versus volume decrease in alcohol and in air

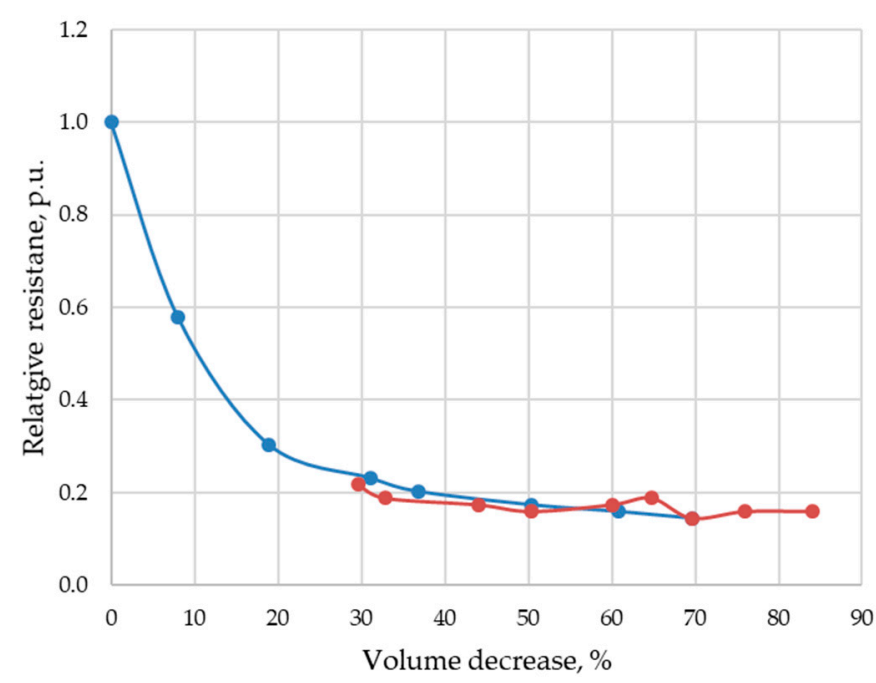

Figure 4. Relative resistance of $\mathrm{CF}$ in air and immersed in ethanol solution versus relative felt volume decrease.

\section{Interpretation of Experimental Data}

We suggest representing the $\mathrm{CF}$ ability to conduct electric current by the average surface conductance (ASC) instead of the well-known use of ASR, which is the inverse of ASC. The advantages of such representation will be seen later. The values of CF ASC immersed in different liquids are placed in Appendix B.

A typical graph of CF ASC in the air versus felt compression D, [\%], is shown in Figure 5. 


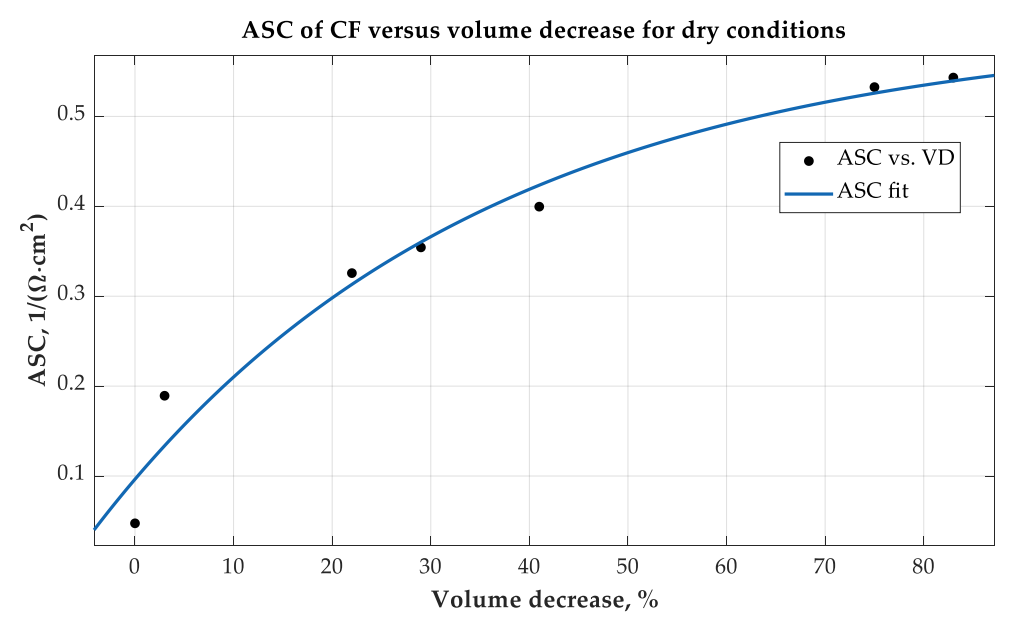

Figure 5. Average surface conductivity (ASC) of a dry CF versus relative felt decrease.

Similar graphs were obtained for CF in glycerol, alcohol, and cyclohexane. The behavior of ASC measured in $\left[\frac{1}{\Omega \cdot \mathrm{cm}^{2}}\right]$ units can be satisfactorily described by an exponential function (3) approximating actual data with a criterion of a precision $\mathrm{R}^{2}=0.986$ :

$$
A S C=a \cdot\left(1-e^{-b \cdot D}\right)+c
$$

Table 4 tabulated values of coefficients $\mathrm{a}, \mathrm{b}$ and $\mathrm{c}$ for approximating dependence of CF ASC versus compression ratio in different liquids. The precision of the theoretical approximation to experimental data is estimated by a coefficient of determination $R^{2}$ having a significantly high value (see Table 4 ). Relative dielectric constant values $\varepsilon_{\mathrm{r}}$ for all environments in which measurements for CF ASC were made, are represented in the first column of Table 4.

Table 4. Coefficients of the approximating function of the relative increase of filaments interconnections for ASC.

\begin{tabular}{cccccc}
\hline \multirow{2}{*}{$\varepsilon_{\mathbf{r}}$} & ASC & \multicolumn{3}{c}{ ASC=a*(1-exp(-b-D)) $+\mathbf{c}$} & \multirow{2}{*}{ Coefficient $\mathbf{R}^{\mathbf{2}}$} \\
\cline { 3 - 5 } & & $\mathbf{a}$ & $\mathbf{b}$ & $\mathbf{c}$ & \\
\hline 1 & dry & 0.5071 & 0.02488 & 0.0933 & 0.969 \\
2.02 & cyclohexane & 0.5024 & 0.02008 & 0.2116 & 0.988 \\
21.6 & ethanol & 0.4269 & 0.02377 & 0.322 & 0.982 \\
42.5 & glycerol & 0.9134 & 0.01278 & 0.0996 & 0.967 \\
\hline
\end{tabular}

It should be noted good conformity of approximating function (3) to measured data. A tendency of coefficient $a$ and $b$ changings versus alteration of liquid dielectric constant can be observed. The first one is grows up with the increase of the dielectric constant whereas the second one goes down. Coefficient $\mathrm{c}$ has no strict propensity and variates around its average magnitude only.

Notably, ASC appears to be dependent on liquid dielectric parameters. Obviously, higher electric permittivity $\varepsilon$ positively influences CF conductivity. CF conductivity increases as a function of $\varepsilon_{\mathrm{r}}$, which could be explained by the increase of the density on internal filaments interconnections both between themselves and with electrodes surfaces. Assuming the density of the interconnections between the carbon filaments is the main felt conductance factor, its relative increase $\left(K_{\text {inc }}\right)_{\text {rel }}$ was calculated as:

$$
\left(K_{\text {inc }}\right)_{\text {rel }}=\frac{(A S C)_{D i}}{(A S C)_{D_{0}}} \cdot \frac{\left(V_{0}\right)}{\left(V_{i}\right)}
$$

where $(\mathrm{ASC})_{\mathrm{Di}}$ and $(\mathrm{ASC})_{\mathrm{D} 0}$ are average specific conductance for $\mathrm{CF}$ having an initial width $\mathrm{D}_{0}$ and the width $D_{i}$ at time $t$. $V_{0}$ designates initial felt and $V_{i}$ its volume at time $t$. A felt width (or equivalently, 
felt volume) decrease was observed as a result of felt compression. Data of interconnection increase of the CF ASC were calculated in accordance with expression (4) and are placed in Appendix C. The persistent increase of interconnection density can be observed that is witnessing the correctness of the proposed model of CF increased conductivity versus its compressing.

$\mathrm{K}_{\text {incr }}$ could be approximated rather exactly by the expression (5) for all liquids. The choice of such exponential function was dictated by its good correlation to measured data. The typical graphic interpretation of (5) is given in Figure 6.

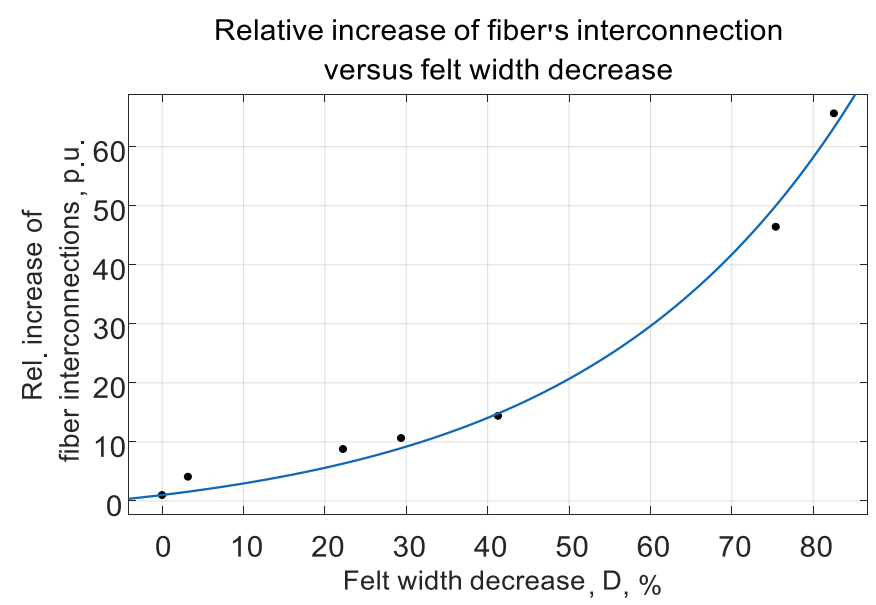

Figure 6. The relative increase of filaments interconnections versus relative volume decrease.

$$
\left(K_{\text {inc }}\right)_{\text {rel }}=A \cdot\left(e^{B \cdot D}-1\right)+1
$$

Comparison of the measurements results with those obtained for a $K_{\text {incr }}$ from the approximation function (5) for each liquid are shown in Table 5.

Table 5. Coefficients in approximating function (5) defining a relative increase of filaments interconnections during felt compression.

\begin{tabular}{ccccc}
\hline \multirow{2}{*}{$\varepsilon_{\mathbf{r}}$} & Liquid & \multicolumn{2}{c}{$\mathbf{K}_{\text {incr }}=\mathbf{A}\left(\mathbf{e}^{\mathbf{B} \cdot \mathbf{D}} \mathbf{- 1}\right)+\mathbf{1}$} & \\
\cline { 3 - 4 } & & $\mathbf{A}$ & $\mathbf{B}$ & \\
& & coeff. $\mathbf{R}^{\mathbf{2}}$ \\
42.5 & dry & 5.499 & 0.03042 & 0.991 \\
21.6 & glycerol & 2.832 & 0.0322 & 0.98 \\
2.02 & ethanol & 0.5523 & 0.05052 & 0.996 \\
& cyclohexane & 0.8402 & 0.03486 & 0.986 \\
\hline
\end{tabular}

\subsection{Analytical Model of CF conductivity}

The electrical conductivity of CF is achieved with carbon (graphite) filaments. More detailed analysis of the $\mathrm{CF}$ electrical conductivity leads to a rigorous conclusion that only those carbon filaments which simultaneously contact both electrodes of the cell sustain electron flow. Therefore, CF conductivity may be assessed as a sum of individual filaments conductivity comprising the total current flow between electrodes. Any individual random disposition of filaments in a CF structure (Figure 7 could be represented by a diagonal of parallelepiped $A B C D A^{*} B^{*} C^{*} D^{*}$, as in Figure 7. For simplicity, individual fibers are considered as thin rods having similar diameters, and therefore, equal cross-sections. This circumstance follows from the data in Table 1. The edge $\mathrm{CC}^{*}$ in the parallelepiped is equal to $C C^{*}=L \cdot \sin \varphi$ and symbolizes a height of a filament having length $L$ and polar disposition angle $\varphi$. In accordance with the working hypothesis, only those filaments contacting both electrodes are participating in current flow; therefore, they must have heights greater than the width (denoted 
as $\mathrm{W}$ ) of the $\mathrm{CF}$. Thus, the totality of fibers whose edge $\mathrm{CC}^{*}>=\mathrm{W}$ contribute to the total electrical conductivity of $\mathrm{CF}$.

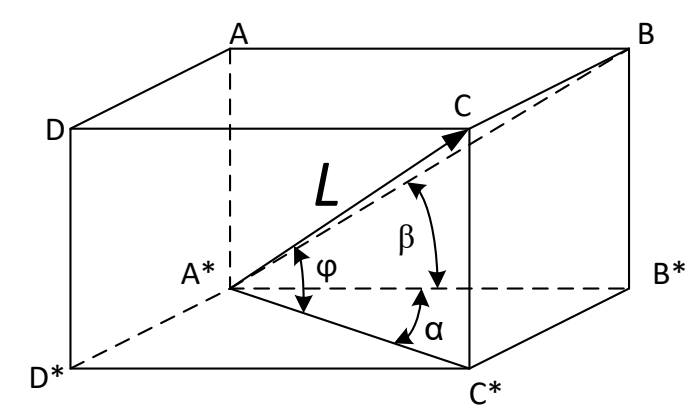

Figure 7. Disposition of individual fiber in the CF frame.

Considering a stochastic length and disposition of filaments in the space of the CF frame, the summing of conductivities can be performed only by a probabilistic approach. Firstly, a stochastic distribution of their lengths (Figure 8a) was measured by a microscope and described by truncated Gauss function. The appropriate parameters were found to include the average length of $\mathrm{L}_{\mathrm{av}}=25 \mathrm{~mm}$, with a standard deviation (STD) of $11 \mathrm{~mm}$.

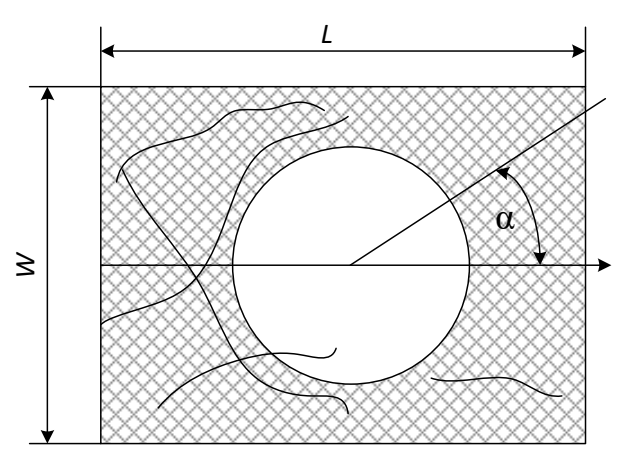

a)

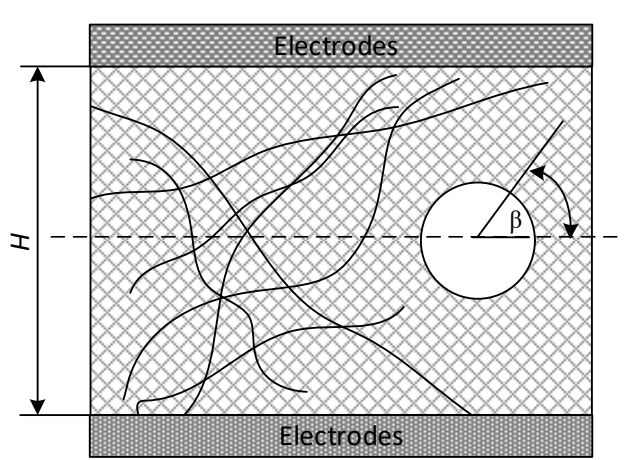

b)

Figure 8. $(\mathbf{a}, \mathbf{b})$ Illustration of the horizontal $(\alpha)$ and vertical $(\beta)$ angles disposition inside carbon frame.

The measurement of the angle $\varphi$ presents a significant technical problem. It was suggested to measure horizontal $(\alpha)$ and vertical $(\beta)$ angles separately by the same optical microscope approach. The histograms of their distributions are shown in Figure 8b,c. In addition, for the simplification of succeeding calculations, it was assumed that both these angles and their distributions are independent. Knowing the horizontal and vertical angles allows calculating the polar angle $\varphi$ as:

$$
\varphi=\arccos \left(\frac{\cos \beta}{\sqrt{\cos ^{2} \alpha+\sin ^{2} \alpha \cdot \cos ^{2} \beta}}\right)
$$

Considering the distribution of horizontal and vertical angles obtained in optical measurements, a Gamma function was selected to describe their probabilities. The expression of the Gamma function (7) includes two parameters ( $a$ and $b$ ) which determine an exact curve of a probability function $\mathrm{p}$ of a variable $x$, it's mean and standard deviation (STD) values.

$$
p(x \mid a, b)=\left\{\begin{array}{ll}
\frac{1}{b^{a} \Gamma(a)} x^{a-1} e^{-\frac{x}{b},} & x \geq 0 \\
0, & x<0
\end{array},\right.
$$


The horizontal angle $\alpha$ distribution is described by parameters $a=1$ and $b=22$. Whereas for angle $\beta$ : $\mathrm{a}=1.4, \mathrm{~b}=20$.

Stochastic distributions of polar angles are illustrated in Figure 8a,b. Where: W denotes the width, $\mathrm{L}$ the length, and $\mathrm{H}$ the height of a $\mathrm{CF}$ in a cell.

Typical histograms of filaments lengths, horizontal, and vertical angles probability distributions that were obtained by optical measurements (see Appendix D) are shown in Figure 9.

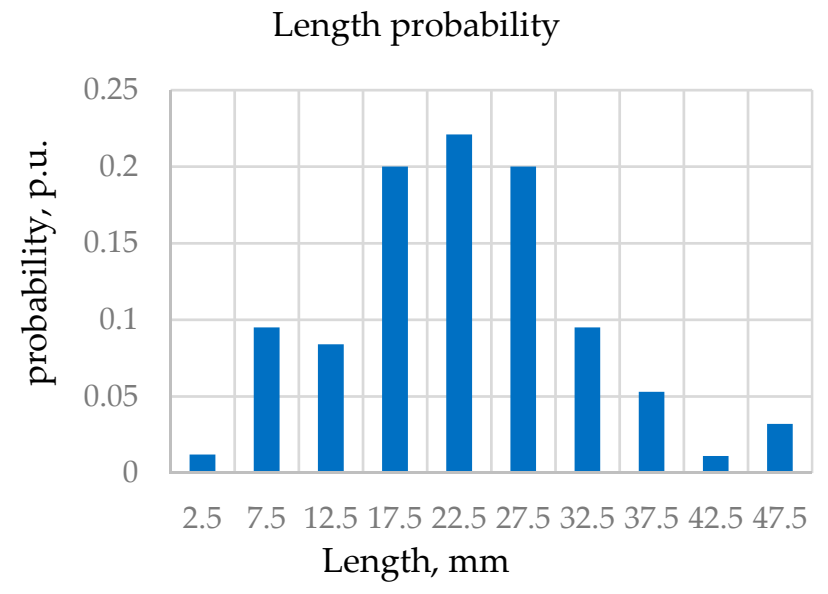

Figure 9. Typical histogram of filaments lengths.

The comparison between the experimental and fitted (gamma distribution) angle spreading is shown in Figure 10.
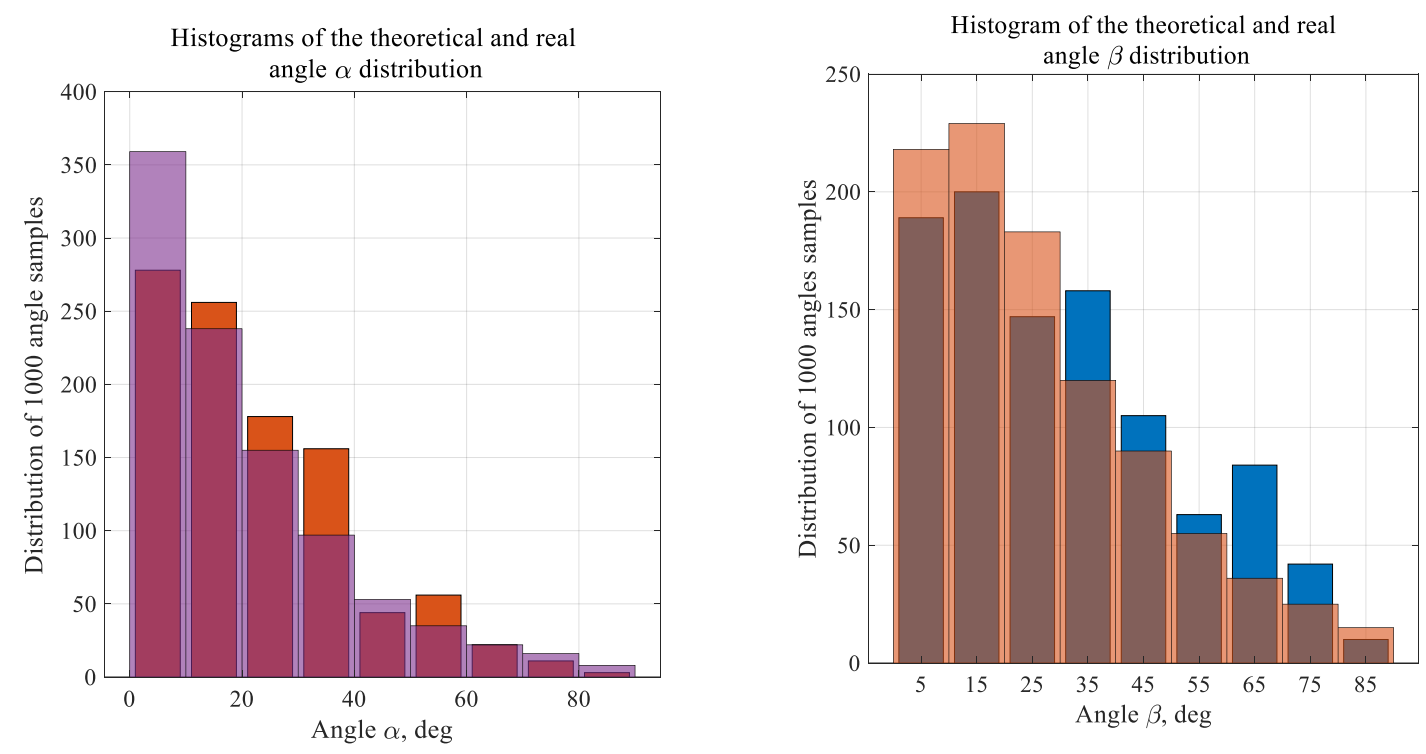

Figure 10. Histograms of a theoretical and experimental data distributions for a horizontal and vertical angle.

Knowing the distributions of both horizontal $\alpha$ and vertical $\beta$ angles and considering their independence, the distribution of a polar angle $\varphi$ can be obtained. The simplest way, for example, is a numerical simulation (see Figure 11) based on the Monte-Carlo approach. 


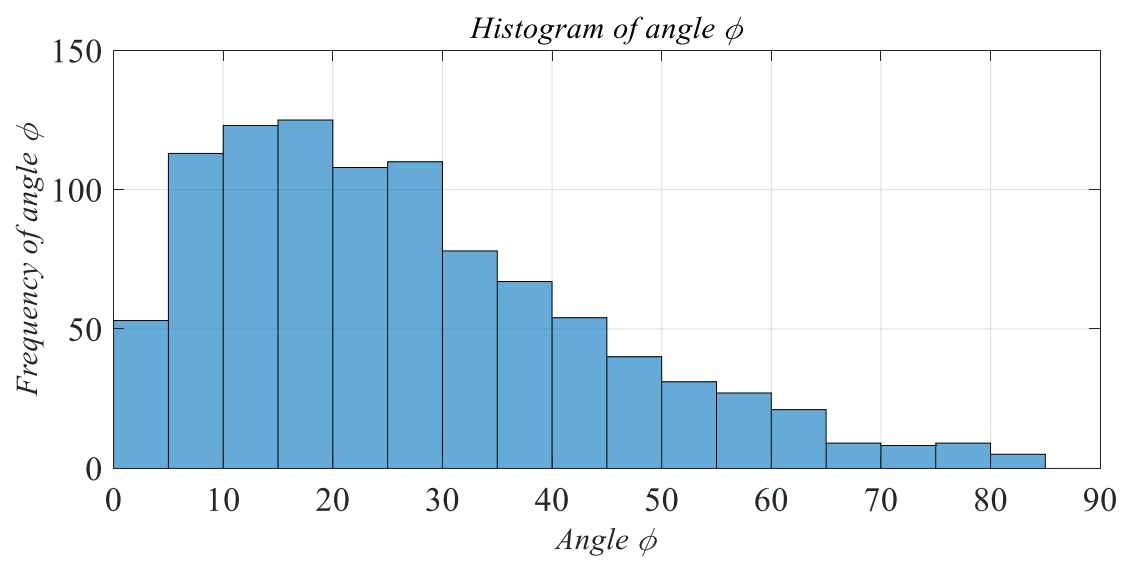

Figure 11. Histogram of theoretical distribution for angles of carbon filaments with respect to the horizontal plane of CF the frame.

Bearing in mind the above-mentioned, a total conductance $(\mathrm{G})$ of a CF can be assessed by the integral is considering conductivities of those filaments, which are connecting both of cell electrodes:

$$
G(h)=g_{\text {carbon }} \cdot A \cdot L_{T} \int_{h}^{\infty}\left(\int_{\arcsin \frac{h}{l}}^{\frac{\pi}{2}} p_{\varphi} d \varphi\right) p_{l} \frac{d l}{l}=g_{\text {carbon }} \cdot \frac{V_{\text {carbon }}}{\rho_{\text {carbon }}} \int_{h}^{\infty}\left(\int_{\arcsin \frac{h}{l}}^{\frac{\pi}{2}} p_{\varphi} d \varphi\right) p_{l} \frac{d l}{l},
$$

where $\mathrm{h}$ is the current thickness of a CF; A-the cross-section of carbon filaments; $\mathrm{L}_{\mathrm{T}}$-the total length of all filaments together; $V_{\text {carbon }}$ - the total volume of all filaments; $g_{\text {carbon }}$-the specific conductivity of a carbon material, $p_{\varphi}, p_{l}$-the probability of a polar angle $\varphi$ and a filament length being equal to $1 ; d \varphi$ and $d l-$ two variables of integration.

Using a numerical approach, the ASC of a CF versus its volume decrease (expressed by its relative squeezing) was obtained that is represented in Figure 12. Dots in Figure 12 denominate ASC values, which were obtained from an integral of conductivity. The solid line represents ASC approximating values obtained from the expression (3) where coefficients are equal to their average magnitudes from Table 4.

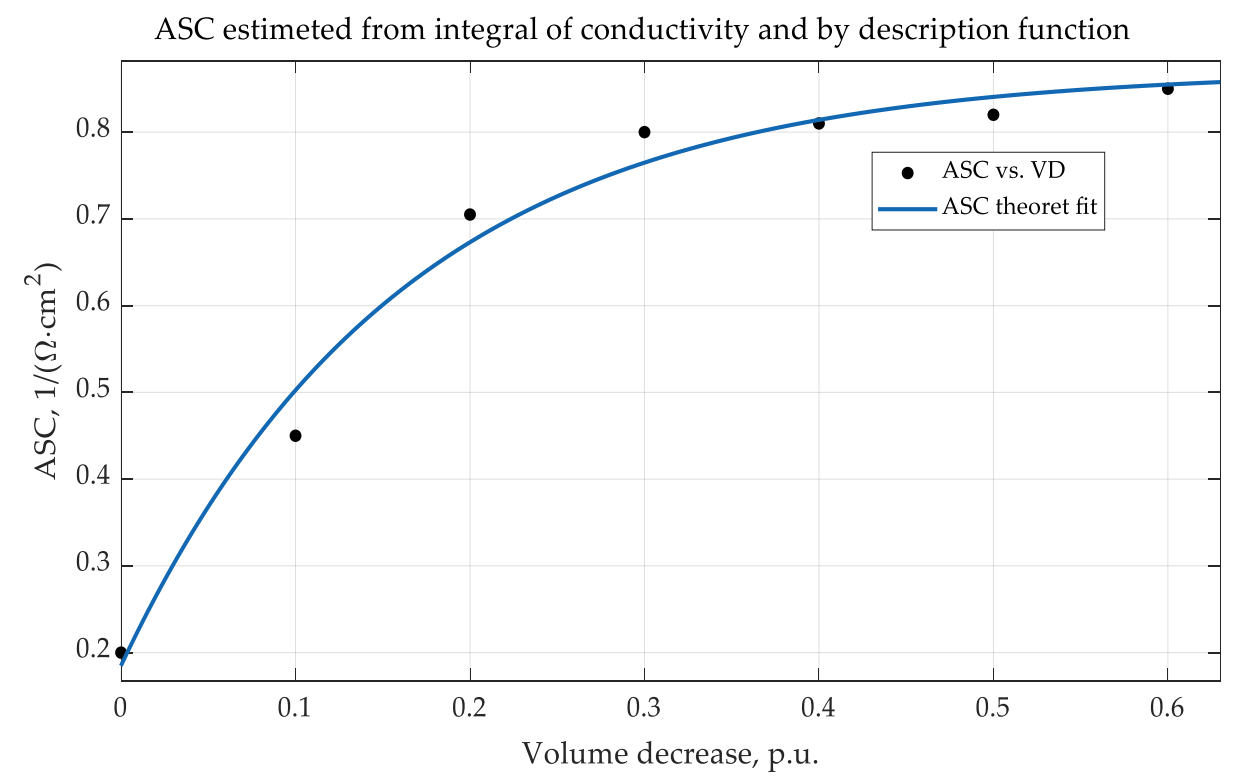

Figure 12. Average square conductivity versus relative CF squeezing. 
The comparison between the measured and theoretically based values shows an accuracy that is represented by $R^{2}=0.984$. This witnesses good applicability of the developed approach.

\section{Results}

(1) The comprehensive investigation of CF electrical conductivity properties was carried in the present article.

(2) The dependence of resistivity versus compressing rate was obtained as in dry conditions (in air) and when CF is immersed in different dielectric liquids.

(3) Electronic resistivity was measured by applying a DC current and an AC current at several specific frequencies $(100 \mathrm{~Hz}, 120 \mathrm{~Hz}, 1 \mathrm{kHz}$ and $10 \mathrm{kHz})$, respectively.

(4) Considering the requirement to verify the influence of dielectric liquid parameters on $\mathrm{CF}$ conductivity, four sets of tests were performed. Resistance was measured in dry conditions and with the CF immersed in different (glycerol, alcohol, and cyclohexane) non-conducting (dielectric) liquids. The use of dielectric liquids instead of real electrolytes was justified to prevent the influence of electrolyte ionic conductivity on the measurement results.

(5) Approximating function with their specific coefficients for description average surface conductivity of $\mathrm{CF}$ was found. The proximity of this function to the real data was determined.

(6) Stochastic dispersion of individual carbon filaments and their disposition angles (vertical and horizontal) were established and were described further by a gamma-distribution function.

(7) Analytical description of CF conductivity based on a stochastic approach and represented by the integral of conductivity was developed.

\section{Discussion}

The results of $\mathrm{CF}$ electrical resistivity properties are extremely important for practical use, as well as for new developments, and research work. Knowing the analytical description of a conductivity paves the way to finding an optimal design of a CF structure able to minimize as an electrical and hydrodynamic resistances. The last may lead to new CF electrodes for different electrochemical application more efficient and useful.

\section{Conclusions}

(1) CF material has widespread requests in different applications, including heating elements and diverse electrochemical cells.

(2) Electrical (electronic) conductivity of CF plays a crucial role for electrons to reach the surface of the electrodes and to participate in reactions. Likewise, electrical resistivity (the inverse of electrical conductivity) plays a significant role in generating heat and causing electrical losses, thus diminishing the efficiency of electrochemical equipment.

(3) Owing to the significant importance of CF resistivity and conductivity for different electrochemical applications, a special comprehensive investigation was carried out aiming to find the magnitudes of these parameters.

(4) It was observed that electrical resistivity was diminished during felt compression, having a non-linear relation versus volume decrease like the negative exponential function. In the initial stage of volume decrease, the resistance drops quickly. However, after $80-60 \%$ of its initial value, additional compression has a negligible effect on conductivity.

(5) Electrical conductivity moderately depends on liquid permittivity properties. Dielectric constant $(\varepsilon)$, among other liquid parameters, obviously has the main role influencing the quantity of interconnection between carbon filaments and electrodes. The increase of $\varepsilon$ causes a slight improvement in CF conductivity.

(6) The theoretical approach based on the stochastic distributions of filaments lengths and their stochastic dispositions inside the felt frame was developed. The conductivity for each current felt 
thickness was estimated by an integral which summarizes the conductivities of all filaments that this time are connecting both of the cell electrodes.

(7) It could be assumed that the type of lengths and angles distribution inside a frame plays a significant role in defining CF conductivity and should be investigated in future research work.

Author Contributions: Conceptualization-M.A.; experiments and methodology-S.L.; validation-M.A. and S.L.; writing—original draft preparation, review and editing-M.A.

Funding: This research received no external funding.

Acknowledgments: The authors would wish to express their deep gratitude to Michael Zinigrad, Alex Kossenko and Engineer Alex Krasnopolsky for their help in comprehensively realizing this research and discussing the obtained results, as well for Larry Loeb for his significant efforts in improving the text of the article.

Conflicts of Interest: The authors declare no conflict of interest.

\section{Appendix A}

Results of CF resistance measurements in ethanol, cyclohexane, and glycerol are represented in Tables A1-A3 correspondingly.

Table A1. CF resistance in ethanol.

\begin{tabular}{|c|c|c|c|c|c|c|c|c|c|c|c|}
\hline \multirow{2}{*}{\multicolumn{3}{|c|}{ Parameters }} & \multicolumn{9}{|c|}{$\mathrm{h}, \mathrm{mm}$} \\
\hline & & & 4.4 & 4.2 & 3.5 & 3.1 & 2.5 & 2.2 & 1.9 & 1.5 & 1.0 \\
\hline & & & \multicolumn{9}{|c|}{ Volume decrease, $\%$} \\
\hline & & & 29.6 & 32.8 & 44.0 & 50.4 & 60.0 & 64.8 & 69.6 & 76.0 & 84.0 \\
\hline \multicolumn{3}{|c|}{$\mathrm{RDC}, \Omega$} & 0.150 & 0.130 & 0.120 & 0.110 & 0.120 & 0.130 & 0.100 & 0.110 & 0.110 \\
\hline \multicolumn{3}{|c|}{ Relative $\mathrm{RDC}, \%$} & 100.0 & 86.7 & 80.0 & 73.3 & 80.0 & 86.7 & 66.7 & 73.3 & 73.3 \\
\hline \multirow{8}{*}{$\mathrm{RAC}, \Omega$} & \multirow{2}{*}{$100 \mathrm{~Hz}$} & Abs & 0.097 & 0.082 & 0.068 & 0.057 & 0.054 & 0.050 & 0.048 & 0.045 & 0.045 \\
\hline & & Rel \% & 0.141 & 0.119 & 0.099 & 0.083 & 0.078 & 0.072 & 0.070 & 0.065 & 0.065 \\
\hline & \multirow{2}{*}{$120 \mathrm{~Hz}$} & Abs & 0.101 & 0.079 & 0.065 & 0.060 & 0.055 & 0.052 & 0.050 & 0.045 & 0.045 \\
\hline & & $\operatorname{Rel} \%$ & 0.146 & 0.114 & 0.094 & 0.087 & 0.080 & 0.075 & 0.072 & 0.065 & 0.065 \\
\hline & \multirow{2}{*}{$1 \mathrm{kHz}$} & Abs & 0.101 & 0.083 & 0.068 & 0.060 & 0.056 & 0.052 & 0.051 & 0.048 & 0.046 \\
\hline & & $\operatorname{Rel} \%$ & 0.146 & 0.120 & 0.099 & 0.087 & 0.081 & 0.075 & 0.074 & 0.070 & 0.067 \\
\hline & \multirow{2}{*}{$10 \mathrm{kHz}$} & Abs & 0.093 & 0.077 & 0.064 & 0.055 & 0.052 & 0.052 & 0.048 & 0.045 & 0.044 \\
\hline & & $\operatorname{Rel} \%$ & 0.135 & 0.112 & 0.093 & 0.080 & 0.075 & 0.075 & 0.070 & 0.065 & 0.064 \\
\hline
\end{tabular}

Table A2. CF resistance in cyclohexane.

\begin{tabular}{|c|c|c|c|c|c|c|c|c|c|c|c|}
\hline \multirow{4}{*}{\multicolumn{2}{|c|}{ Parameter }} & \multicolumn{10}{|c|}{$\mathrm{h}, \mathrm{mm}$} \\
\hline & & 6.62 & 6.12 & 5.67 & 5.32 & 4.77 & 4.12 & 3.62 & 2.92 & 2.12 & 1.22 \\
\hline & & \multicolumn{10}{|c|}{ Volume decrease, $\%$} \\
\hline & & 0 & 8 & 15 & 21 & 29 & 40 & 48 & 59 & 71 & 86 \\
\hline \multicolumn{2}{|c|}{ Rdc, $\Omega$} & 0.18 & 0.13 & 0.11 & 0.105 & 0.1 & 0.09 & 0.08 & 0.08 & 0.08 & 0.08 \\
\hline \multicolumn{2}{|c|}{ Relative $\mathrm{RDC}_{\mathrm{DC}} \%$} & 100.0 & 72.2 & 61.1 & 58.3 & 55.6 & 50.0 & 44.4 & 44.4 & 44.4 & 44.4 \\
\hline \multirow{4}{*}{ Rac, $\Omega$} & $100, \mathrm{~Hz}$ & 0.169 & 0.12 & 0.093 & 0.081 & 0.073 & 0.065 & 0.062 & 0.058 & 0.053 & 0.046 \\
\hline & $120, \mathrm{~Hz}$ & 0.173 & 0.102 & 0.09 & 0.083 & 0.069 & 0.064 & 0.059 & 0.055 & 0.052 & 0.046 \\
\hline & $1, \mathrm{kHz}$ & 0.171 & 0.11 & 0.093 & 0.08 & 0.068 & 0.065 & 0.06 & 0.058 & 0.054 & 0.049 \\
\hline & $10, \mathrm{kHz}$ & 0.162 & 0.099 & 0.09 & 0.075 & 0.068 & 0.061 & 0.058 & 0.058 & 0.054 & 0.046 \\
\hline
\end{tabular}


Table A3. CF resistance in glycerol.

\begin{tabular}{|c|c|c|c|c|c|c|c|c|c|c|}
\hline \multirow{2}{*}{\multicolumn{3}{|c|}{ Parameters }} & \multicolumn{8}{|c|}{$\mathrm{h}, \mathrm{mm}$} \\
\hline & & & 6.25 & 5.75 & 5.07 & 4.31 & 3.95 & 3.1 & 2.45 & 1.9 \\
\hline & & & \multicolumn{8}{|c|}{ Volume decrease, $\%$} \\
\hline & & & 0.0 & 8.0 & 18.9 & 31.0 & 36.8 & 50.4 & 60.8 & 69.6 \\
\hline \multicolumn{3}{|c|}{$\mathrm{RDC}, \Omega$} & 0.69 & 0.4 & 0.21 & 0.16 & 0.14 & 0.12 & 0.11 & 0.1 \\
\hline \multicolumn{3}{|c|}{ Relative $\mathrm{RDC}_{\mathrm{DC}} \%$} & 100.0 & 58.0 & 30.4 & 23.2 & 20.3 & 17.4 & 15.9 & 14.5 \\
\hline \multirow{8}{*}{ Rac, $\Omega$} & \multirow{2}{*}{$100 \mathrm{~Hz}$} & Abs & 0.59 & 0.333 & 0.185 & 0.118 & 0.09 & 0.074 & 0.067 & 0.056 \\
\hline & & $\operatorname{Rel} \%$ & 0.855 & 0.483 & 0.268 & 0.171 & 0.130 & 0.107 & 0.097 & 0.081 \\
\hline & \multirow{2}{*}{$120 \mathrm{~Hz}$} & Abs & 0.59 & 0.332 & 0.186 & 0.116 & 0.091 & 0.072 & 0.063 & 0.052 \\
\hline & & $\operatorname{Rel} \%$ & 0.86 & 0.48 & 0.27 & 0.17 & 0.13 & 0.10 & 0.09 & 0.08 \\
\hline & \multirow{2}{*}{$1 \mathrm{kHz}$} & Abs & 0.591 & 0.331 & 0.186 & 0.121 & 0.094 & 0.075 & 0.067 & 0.056 \\
\hline & & $\operatorname{Rel} \%$ & 0.857 & 0.480 & 0.270 & 0.175 & 0.136 & 0.109 & 0.097 & 0.081 \\
\hline & \multirow{2}{*}{$10 \mathrm{kHz}$} & Abs & 0.527 & 0.291 & 0.177 & 0.112 & 0.09 & 0.071 & 0.063 & 0.054 \\
\hline & & $\operatorname{Rel} \%$ & 0.764 & 0.422 & 0.257 & 0.162 & 0.130 & 0.103 & 0.091 & 0.078 \\
\hline
\end{tabular}

\section{Appendix B}

Includes data of CF ASC in different liquids that were calculated on the base of CF resistivity values are represented in Appendix A.

Table A4. CF ASC in the air.

\begin{tabular}{|c|c|c|c|c|c|c|c|c|}
\hline \multirow{4}{*}{\multicolumn{2}{|c|}{ Parameter }} & \multicolumn{7}{|c|}{$\mathrm{h}, \mathrm{mm}$} \\
\hline & & 6.3 & 6.1 & 4.9 & 4.45 & 3.7 & 1.55 & 1.1 \\
\hline & & \multicolumn{7}{|c|}{ Volume decrease, $\%$} \\
\hline & & 0 & 3 & 22 & 29 & 41 & 75 & 83 \\
\hline \multicolumn{2}{|l|}{ Rdc, $\Omega$} & 0.65 & 0.22 & 0.13 & 0.1 & 0.09 & 0.07 & 0.08 \\
\hline \multirow{4}{*}{ Rac, $\Omega$} & $100, \mathrm{~Hz}$ & 0.74 & 0.17 & 0.098 & 0.092 & 0.08 & 0.059 & 0.059 \\
\hline & $120, \mathrm{~Hz}$ & 0.737 & 0.168 & 0.095 & 0.095 & 0.082 & 0.061 & 0.058 \\
\hline & $1, \mathrm{kHz}$ & 0.737 & 0.17 & 0.101 & 0.093 & 0.086 & 0.061 & 0.057 \\
\hline & $10, \mathrm{kHz}$ & 0.665 & 0.163 & 0.095 & 0.091 & 0.08 & 0.063 & 0.058 \\
\hline \multicolumn{2}{|c|}{ ASCDC, $1 /\left(\Omega \cdot \mathrm{cm}^{2}\right)$} & 0.051 & 0.152 & 0.256 & 0.333 & 0.370 & 0.476 & 0.417 \\
\hline \multirow{4}{*}{$\mathrm{ASC}_{\mathrm{AC}}, 1 /\left(\Omega \cdot \mathrm{cm}^{2}\right)$} & $100, \mathrm{~Hz}$ & 0.045 & 0.196 & 0.340 & 0.362 & 0.417 & 0.565 & 0.565 \\
\hline & $120, \mathrm{~Hz}$ & 0.045 & 0.198 & 0.351 & 0.351 & 0.407 & 0.546 & 0.575 \\
\hline & $1, \mathrm{kHz}$ & 0.045 & 0.196 & 0.330 & 0.358 & 0.388 & 0.546 & 0.585 \\
\hline & $10, \mathrm{kHz}$ & 0.050 & 0.204 & 0.351 & 0.366 & 0.417 & 0.529 & 0.575 \\
\hline
\end{tabular}


Table A5. CF ASC in glycerol

\begin{tabular}{|c|c|c|c|c|c|c|c|c|c|c|}
\hline \multirow{4}{*}{\multicolumn{3}{|c|}{ Parameters }} & \multicolumn{8}{|c|}{$\mathrm{h}, \mathrm{mm}$} \\
\hline & & & 6.25 & 5.75 & 5.07 & 4.31 & 3.95 & 3.1 & 2.45 & 1.9 \\
\hline & & & \multicolumn{8}{|c|}{ Volume decrease, $\%$} \\
\hline & & & 0.0 & 8.0 & 18.9 & 31.0 & 36.8 & 50.4 & 60.8 & 69.6 \\
\hline \multicolumn{3}{|c|}{$\mathrm{RDC}, \Omega$} & 0.69 & 0.4 & 0.21 & 0.16 & 0.14 & 0.12 & 0.11 & 0.1 \\
\hline \multicolumn{3}{|c|}{ Relative $\mathrm{RDC}_{\mathrm{DC}} \%$} & 100.0 & 58.0 & 30.4 & 23.2 & 20.3 & 17.4 & 15.9 & 14.5 \\
\hline \multirow{8}{*}{ Rac, $\Omega$} & \multirow{2}{*}{$100 \mathrm{~Hz}$} & Abs & 0.59 & 0.333 & 0.185 & 0.118 & 0.09 & 0.074 & 0.067 & 0.056 \\
\hline & & $\operatorname{Rel} \%$ & 0.855 & 0.483 & 0.268 & 0.171 & 0.130 & 0.107 & 0.097 & 0.081 \\
\hline & \multirow{2}{*}{$120 \mathrm{~Hz}$} & Abs & 0.59 & 0.332 & 0.186 & 0.116 & 0.091 & 0.072 & 0.063 & 0.052 \\
\hline & & $\operatorname{Rel} \%$ & 0.86 & 0.48 & 0.27 & 0.17 & 0.13 & 0.10 & 0.09 & 0.08 \\
\hline & \multirow{2}{*}{$1 \mathrm{kHz}$} & Abs & 0.591 & 0.331 & 0.186 & 0.121 & 0.094 & 0.075 & 0.067 & 0.056 \\
\hline & & $\operatorname{Rel} \%$ & 0.857 & 0.480 & 0.270 & 0.175 & 0.136 & 0.109 & 0.097 & 0.081 \\
\hline & \multirow{2}{*}{$10 \mathrm{kHz}$} & Abs & 0.527 & 0.291 & 0.177 & 0.112 & 0.09 & 0.071 & 0.063 & 0.054 \\
\hline & & $\operatorname{Rel} \%$ & 0.764 & 0.422 & 0.257 & 0.162 & 0.130 & 0.103 & 0.091 & 0.078 \\
\hline
\end{tabular}

Table A6. CF ASC in ethanol.

\begin{tabular}{|c|c|c|c|c|c|c|c|c|c|c|c|}
\hline \multirow{4}{*}{\multicolumn{3}{|c|}{ Parameters }} & \multicolumn{9}{|c|}{$\mathrm{h}, \mathrm{mm}$} \\
\hline & & & 4.4 & 4.2 & 3.5 & 3.1 & 2.5 & 2.2 & 1.9 & 1.5 & 1.0 \\
\hline & & & \multicolumn{9}{|c|}{ Volume decrease, \% } \\
\hline & & & 29.6 & 32.8 & 44.0 & 50.4 & 60.0 & 64.8 & 69.6 & 76.0 & 84.0 \\
\hline \multicolumn{3}{|c|}{$\mathrm{RDC}, \Omega$} & 0.150 & 0.130 & 0.120 & 0.110 & 0.120 & 0.130 & 0.100 & 0.110 & 0.110 \\
\hline \multicolumn{3}{|c|}{ Relative RDC, \% } & 100.0 & 86.7 & 80.0 & 73.3 & 80.0 & 86.7 & 66.7 & 73.3 & 73.3 \\
\hline \multirow{8}{*}{$\mathrm{R}_{\mathrm{AC}}, \Omega$} & \multirow{2}{*}{$100 \mathrm{~Hz}$} & Abs & 0.097 & 0.082 & 0.068 & 0.057 & 0.054 & 0.050 & 0.048 & 0.045 & 0.045 \\
\hline & & $\operatorname{Rel} \%$ & 0.141 & 0.119 & 0.099 & 0.083 & 0.078 & 0.072 & 0.070 & 0.065 & 0.065 \\
\hline & \multirow{2}{*}{$120 \mathrm{~Hz}$} & Abs & 0.101 & 0.079 & 0.065 & 0.060 & 0.055 & 0.052 & 0.050 & 0.045 & 0.045 \\
\hline & & $\operatorname{Rel} \%$ & 0.146 & 0.114 & 0.094 & 0.087 & 0.080 & 0.075 & 0.072 & 0.065 & 0.065 \\
\hline & \multirow{2}{*}{$1 \mathrm{kHz}$} & Abs & 0.101 & 0.083 & 0.068 & 0.060 & 0.056 & 0.052 & 0.051 & 0.048 & 0.046 \\
\hline & & $\operatorname{Rel} \%$ & 0.146 & 0.120 & 0.099 & 0.087 & 0.081 & 0.075 & 0.074 & 0.070 & 0.067 \\
\hline & \multirow{2}{*}{$10 \mathrm{kHz}$} & Abs & 0.093 & 0.077 & 0.064 & 0.055 & 0.052 & 0.052 & 0.048 & 0.045 & 0.044 \\
\hline & & $\operatorname{Rel} \%$ & 0.135 & 0.112 & 0.093 & 0.080 & 0.075 & 0.075 & 0.070 & 0.065 & 0.064 \\
\hline
\end{tabular}


Table A7. CF ASC in cyclohexane.

\begin{tabular}{|c|c|c|c|c|c|c|c|c|c|c|c|}
\hline \multirow{4}{*}{\multicolumn{2}{|c|}{ Parameter }} & \multicolumn{10}{|c|}{$\mathrm{h}, \mathrm{mm}$} \\
\hline & & 6.62 & 6.12 & 5.67 & 5.32 & 4.77 & 4.12 & 3.62 & 2.92 & 2.12 & 1.22 \\
\hline & & \multicolumn{10}{|c|}{ Volume decrease, $\%$} \\
\hline & & 0 & 8 & 15 & 21 & 29 & 40 & 48 & 59 & 71 & 86 \\
\hline \multicolumn{2}{|c|}{$\mathrm{Rdc}, \Omega$} & 0.18 & 0.13 & 0.11 & 0.105 & 0.1 & 0.09 & 0.08 & 0.08 & 0.08 & 0.08 \\
\hline \multirow{4}{*}{ Rac, $\Omega$} & $100, \mathrm{~Hz}$ & 0.169 & 0.12 & 0.093 & 0.081 & 0.073 & 0.065 & 0.062 & 0.058 & 0.053 & 0.046 \\
\hline & $120, \mathrm{~Hz}$ & 0.173 & 0.102 & 0.09 & 0.083 & 0.069 & 0.064 & 0.059 & 0.055 & 0.052 & 0.046 \\
\hline & $1, \mathrm{kHz}$ & 0.171 & 0.11 & 0.093 & 0.08 & 0.068 & 0.065 & 0.06 & 0.058 & 0.054 & 0.049 \\
\hline & $10, \mathrm{kHz}$ & 0.162 & 0.099 & 0.09 & 0.075 & 0.068 & 0.061 & 0.058 & 0.058 & 0.054 & 0.046 \\
\hline \multicolumn{2}{|c|}{ ASCDC, $1 /\left(\Omega \cdot \mathrm{cm}^{2}\right)$} & 0.185 & 0.256 & 0.303 & 0.317 & 0.333 & 0.370 & 0.417 & 0.417 & 0.417 & 0.417 \\
\hline \multirow{4}{*}{$\begin{array}{c}\text { ASCAC, } \\
1 /\left(\Omega \cdot \mathrm{cm}^{2}\right)\end{array}$} & $100, \mathrm{~Hz}$ & 0.197 & 0.278 & 0.358 & 0.412 & 0.457 & 0.513 & 0.538 & 0.575 & 0.629 & 0.725 \\
\hline & $120, \mathrm{~Hz}$ & 0.193 & 0.327 & 0.370 & 0.402 & 0.483 & 0.521 & 0.565 & 0.606 & 0.641 & 0.725 \\
\hline & $1, \mathrm{kHz}$ & 0.195 & 0.303 & 0.358 & 0.417 & 0.490 & 0.513 & 0.556 & 0.575 & 0.617 & 0.680 \\
\hline & $10, \mathrm{kHz}$ & 0.206 & 0.337 & 0.370 & 0.444 & 0.490 & 0.546 & 0.575 & 0.575 & 0.617 & 0.725 \\
\hline
\end{tabular}

\section{Appendix C}

This section represents data of the relative increase of carbon filaments interconnections was obtained in accordance with Equation (4) and on the basis of the data in Appendix B.

Table A8. Relative increase of filaments interconnections in glycerol.

\begin{tabular}{|c|c|c|c|c|c|c|c|c|}
\hline \multirow{4}{*}{ Parameter } & \multicolumn{8}{|c|}{$\mathrm{h}, \mathrm{mm}$} \\
\hline & 5.4 & 4.8 & 4.4 & 4 & 3.2 & 3 & 2.5 & 2 \\
\hline & \multicolumn{7}{|c|}{ Volume decrease, $\%$} & \\
\hline & 0 & 10 & 16 & 22 & 35 & 38 & 46 & 54 \\
\hline Average ASC, $1 /(\Omega \cdot \mathrm{cm} 2)$ & 0.105 & 0.193 & 0.263 & 0.334 & 0.423 & 0.495 & 0.448 & 0.577 \\
\hline Volume of felt, $\mathrm{cm}^{3}$ & 16.2 & 14.4 & 13.2 & 12 & 9.6 & 9 & 7.5 & 6 \\
\hline Relative felt volume, p.u. & 1 & 1.13 & 1.23 & 1.35 & 1.69 & 1.80 & 2.16 & 2.70 \\
\hline Relative increase of interconnections & 1 & 2.07 & 3.08 & 4.30 & 6.81 & 8.50 & 9.23 & 14.87 \\
\hline
\end{tabular}

Table A9. Relative increase of filaments interconnections in ethanol.

\begin{tabular}{|c|c|c|c|c|c|c|c|c|c|}
\hline \multirow{4}{*}{ Parameter } & \multicolumn{7}{|c|}{$\mathrm{h}, \mathrm{mm}$} & \multirow[b]{2}{*}{1.5} & \multirow[b]{2}{*}{1} \\
\hline & 4.4 & 4.2 & 3.5 & 3.1 & 2.5 & 2.2 & 1.9 & & \\
\hline & \multicolumn{7}{|c|}{ Volume decrease, $\%$} & & \\
\hline & 0 & 3 & 14 & 21 & 30 & 35 & 40 & 46 & 54 \\
\hline $\begin{array}{c}\text { Average ASC, } \\
1 /(\Omega \cdot \mathrm{cm} 2)\end{array}$ & 0.31 & 0.37 & 0.44 & 0.50 & 0.52 & 0.55 & 0.59 & 0.62 & 0.63 \\
\hline Volume of felt, $\mathrm{cm}^{3}$ & 13.2 & 12.6 & 10.5 & 9.3 & 7.5 & 6.6 & 5.7 & 4.5 & 3 \\
\hline $\begin{array}{l}\text { Relative felt volume, } \\
\text { p.u. }\end{array}$ & 1 & 1.05 & 1.26 & 1.42 & 1.76 & 2.00 & 2.32 & 2.93 & 4.40 \\
\hline $\begin{array}{l}\text { Relative increase of } \\
\text { interconnections }\end{array}$ & 1 & 1.27 & 1.82 & 2.31 & 3.01 & 3.60 & 4.44 & 5.93 & 9.01 \\
\hline
\end{tabular}

Table A10. Relative increase of filaments interconnections in cyclohexane.

\begin{tabular}{|c|c|c|c|c|c|c|c|c|c|}
\hline \multirow{4}{*}{ Parameter } & \multicolumn{9}{|c|}{$\mathrm{h}, \mathrm{mm}$} \\
\hline & 6.62 & 5.67 & 5.32 & 4.77 & 4.12 & 2.92 & 2.12 & 1.62 & 1.22 \\
\hline & \multicolumn{9}{|c|}{ Volume decrease, $\%$} \\
\hline & 0 & 15 & 21 & 29 & 40 & 59 & 71 & 79 & 86 \\
\hline Average ASC, $1 /(\Omega \cdot \mathrm{cm} 2)$ & 0.19 & 0.35 & 0.39 & 0.44 & 0.48 & 0.54 & 0.58 & 0.62 & 0.64 \\
\hline Volume of felt, $\mathrm{cm}^{3}$ & 19.86 & 17.01 & 15.96 & 14.31 & 12.36 & 8.76 & 6.36 & 4.86 & 3.66 \\
\hline Relative felt volume p.u. & 1.00 & 1.17 & 1.24 & 1.39 & 1.61 & 2.27 & 3.12 & 4.09 & 5.43 \\
\hline $\begin{array}{c}\text { Relative increase of } \\
\text { interconnections, p.u. }\end{array}$ & 1.00 & 2.11 & 2.50 & 3.18 & 4.00 & 6.40 & 9.34 & 13.14 & 17.94 \\
\hline
\end{tabular}




\section{Appendix D}

Includes CF magnified images foe creating histogram of horizontal and vertical angles of carbon filaments inside felt frame.

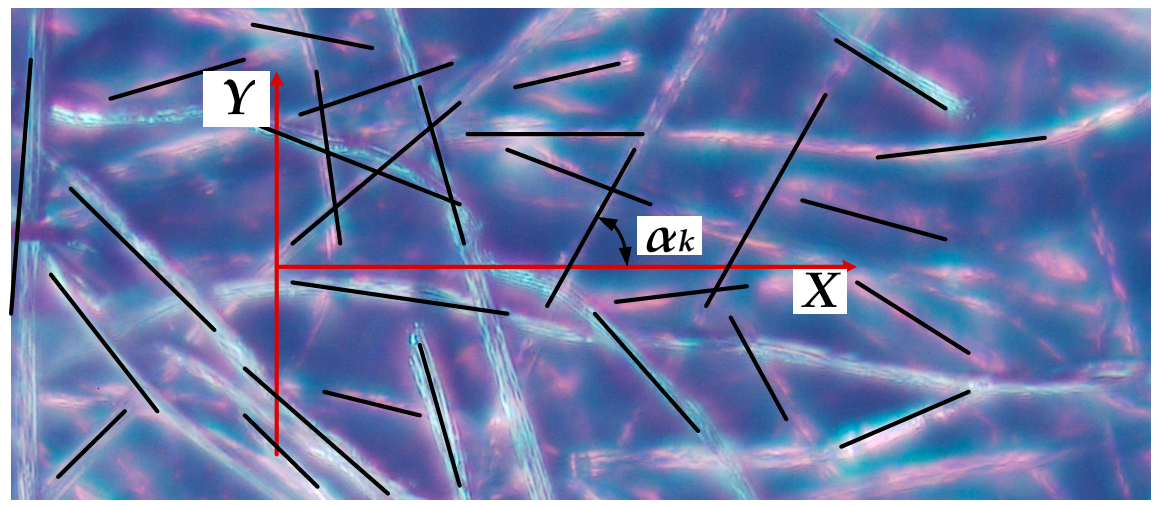

Figure A1. Microscope image of a CF filament dispositions for creating the filaments angles histogram.

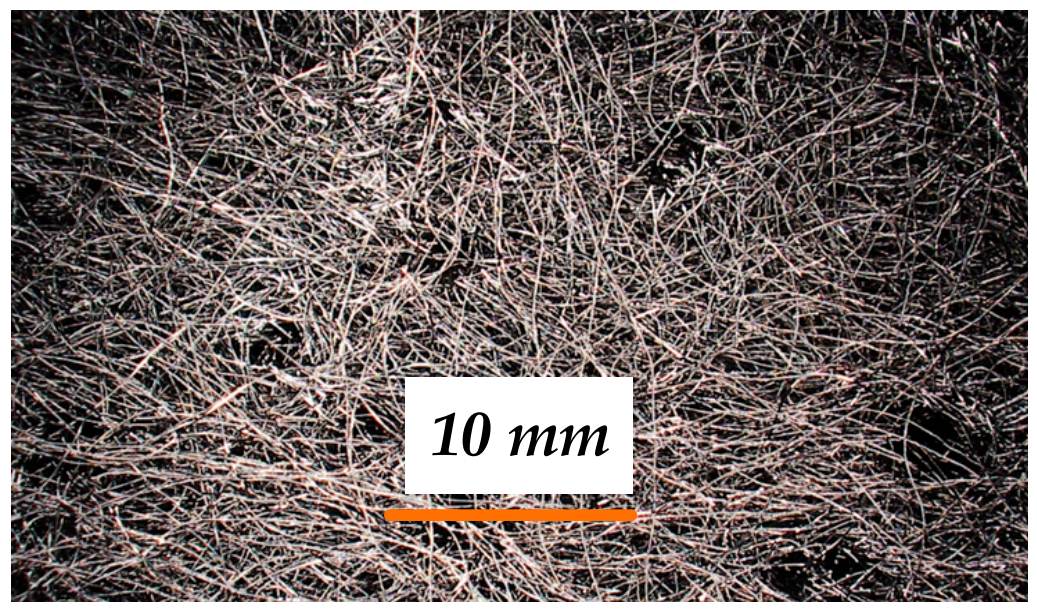

Figure A2. Microscope image of a CF for creating filaments lengths histogram.

\section{References}

1. Fialkov, A. Carbon application in chemical power sources. Russ. J. Electrochem. 2000, 36, 345-366. [CrossRef]

2. Zhao, J.G.; Li, K.Z.; Li, H.J.; Wang, C. The influence of thermal gradient on pyrocarbon deposition in carbon/carbon composites during the CVI process. Carbon 2006, 44, 786-791. [CrossRef]

3. Chugh, R.; Chung, D.D.L. Flexible graphite as a heating element. Carbon 2002, 40, 2285-2289. [CrossRef]

4. Martinez-Huitle, C.A.; Ferro, S. Electrochemical oxidation of organic pollutants for the wastewater treatment: direct and indirect processes. Chem. Soc. Rev. 2006, 35, 1324-1340. [CrossRef] [PubMed]

5. Gözmen, B.; Oturan, M.A.; Oturan, N.; Erbatur, O. Indirect electrochemical treatment of bisphenol A in water via electrochemically generated Fenton's reagent. Environ. Sci. Technol. 2003, 37, 3716-3723.

6. Langlois, S.; Coeuret, F. Flow-through and flow-by porous electrodes of nickel foam. I. Material characterization. J. Appl. Electrochem. 1989, 19, 43-50. [CrossRef]

7. Le, T.X.H.; Bechelany, M.; Cretin, M. Carbon felt based-electrodes for energy and environmental applications: A review. Carbon 2017, 122, 564-591.

8. Joerissen, L.; Garche, J.; Fabjan, C.; Tomazic, G. Possible use of vanadium redox-flow batteries for energy storage in small grids and stand-alone photovoltaic systems. J. Power Sources 2004, 127, 98-104. [CrossRef]

9. Parasuraman, A.; Lim, T.M.; Menictas, C.; Skyllas-Kazacos, M. Review of material research and development for vanadium redox flow battery applications. Electrochim. Acta 2013, 101, 27-40. [CrossRef]

10. Rahman, F.; Skyllas-Kazacos, M. Vanadium redox battery: Positive half-cell electrolyte studies. J. Power Sources 2009, 189, 1212-1219. [CrossRef] 
11. Zhao, P.; Zhang, H.; Zhou, H.; Chen, J.; Gao, S.; Yi, B. Characteristics and performance of $10 \mathrm{~kW}$ class all-vanadium redox-flow battery stack. J. Power Sources 2006, 162, 1416-1420. [CrossRef]

12. Wang, Q.; Qu, Z.G.; Jiang, Z.Y.; Yang, W.W. Experimental study on the performance of a vanadium redox flow battery with non-uniformly compressed carbon felt electrode. Appl. Energy 2018, 213, 293-305. [CrossRef]

13. González, Z.; Sánchez, A.; Blanco, C.; Granda, M.; Menéndez, R.; Santamaría, R. Enhanced performance of a Bi-modified graphite felt as the positive electrode of a vanadium redox flow battery. Electrochem. Commun. 2011, 13, 1379-1382. [CrossRef]

14. Gundlapalli, R.; Jayanti, S. Effect of electrode compression and operating parameters on the performance of large vanadium redox flow battery cells. J. Power Sources 2019, 427, 231-242. [CrossRef]

15. Becker, M.; Bredemeyer, N.; Tenhumberg, N.; Turek, T. Kinetic studies at carbon felt electrodes for vanadium redox-flow batteries under controlled transfer current density conditions. Electrochim. Acta 2017, 252, 12-24. [CrossRef]

16. Flox, C.; Skoumal, M.; Rubio-Garcia, J.; Andreu, T.; Morante, J.R. Strategies for enhancing electrochemical activity of carbon-based electrodes for all-vanadium redox flow batteries. Appl. Energy 2013, 109, $344-351$. [CrossRef]

17. Huong Le, T.X.; Bechelany, M.; Cretin, M. Carbon felt based-electrodes for energy and environmental applications: A review. Carbon 2017, 122, 564-591. [CrossRef]

18. Averbukh, M.; Pozin, A.; Sukoriansky, S. Electrolyte Pumping Optimization in Already Manufactured Vanadium Redox Battery Based on Experimentally Determined Electrical and Hydrodynamic Losses. J. Energy Eng. 2016, 143, 04016050. [CrossRef]

19. Yue, L.; Li, W.; Sun, F.; Zhao, L.; Xing, L. Highly hydroxylated carbon fibres as electrode materials of all-vanadium redox flow battery. Carbon 2010, 48, 3079-3090. [CrossRef]

20. Park, S.K.; Shim, J.; Yang, J.H.; Jin, C.S.; Lee, B.S.; Lee, Y.S.; Shin, K.H.; Jeon, J.D. The influence of compressed carbon felt electrodes on the performance of a vanadium redox flow battery. Electrochim. Acta 2014, 116, 447-452. [CrossRef]

21. Kossenko, A.; Lugovskoy, S.; Averbukh, M. Electric and Hydraulic Properties of Carbon Felt Immersed in Different Dielectric Liquids. Materials 2018, 11, 650. [CrossRef] [PubMed]

22. Gonzalez-Garcia, J.; Bonete, P.; Exposito, E.; Montiel, V.; Aldaz, A.; Torregrosa-Maciá, R. Characterization of a carbon felt electrode: structural and physical properties. J. Mater. Chem. 1999, 9, 419-426. [CrossRef]

23. Zhou, H.; Zhang, H.; Zhao, P.; Yi, B. A comparative study of carbon felt and activated carbon-based electrodes for sodium polysulfide/bromine redox flow battery. Electrochim. Acta 2006, 51, 6304-6312. [CrossRef]

24. Wang, W.; Wang, X. Investigation of Ir-modified carbon felt as the positive electrode of an all-vanadium redox flow battery. Electrochim. Acta 2007, 52, 6755-6762. [CrossRef]

25. Li, X.; Huang, K.; Liu, S.; Ning, T.; Chen, L. Characteristics of graphite felt electrode electrochemically oxidized for vanadium redox battery application. Trans. Nonferrous Met. Soc. China 2007, 17, 195-199. [CrossRef]

26. André, J.; Antoni, L.; Petit, J.P.; De Vito, E.; Montani, A. Electrical contact resistance between stainless steel bipolar plate and carbon felt in PEFC: A comprehensive study. Int. J. Hydrogen Energy 2009, 34, 3125-3133. [CrossRef]

27. Lee, M.S.; Chen, L.J.; He, Z.R.; Yang, S.H. The development of a heterogeneous composite bipolar plate of a proton exchange membrane fuel cell. J. Electrochem. Energy Convers. Storage 2005, 2, 14-19. [CrossRef]

28. Qian, P.; Zhang, H.; Chen, J.; Wen, Y.; Luo, Q.; Liu, Z.; You, D.; Yi, B. A novel electrode-bipolar plate assembly for vanadium redox flow battery applications. J. Power Sources 2008, 175, 613-620. [CrossRef]

29. Castaneda, L.F.; Walsh, F.C.; Nava, J.L.; de Leon, C.P. Graphite felt as a versatile electrode material: Properties, reaction environment, performance and applications. Electrochim. Acta 2017, 258, 1115-1139. [CrossRef]

30. Chang, T.C.; Zhang, J.P.; Fuh, Y.K. Electrical, mechanical and morphological properties of compressed carbon felt electrodes in vanadium redox flow battery. J. Power Sources 2014, 245, 66-75. [CrossRef]

31. Weber, A.Z.; Mench, M.M.; Meyers, J.P.; Ross, P.N.; Gostick, J.T.; Liu, Q. Redox flow batteries: A review. J. Appl. Electrochem. 2011, 41, 1137. [CrossRef] 
32. Choe, J.; Kim, K.H. Corrugated carbon/epoxy composite bipolar plate for vanadium redox flow batteries. Compos. Struct. 2015, 119, 534-542. [CrossRef]

33. Graphite Machining, Molding\&Manufacturing|Mersen Graphite. Available online: http://www.graphiteeng.com (accessed on 7 March 2017). 